\title{
Knowledge and usage of prevention measures against urinary tract infections among young women
}

\author{
OLIVIA CYRANA-G, MARTA JAGODZIŃSKA ${ }^{A, B}$, D, MICHAŁ NOWICKIA, D-F \\ ORCID ID: 0000-0001-6600-1514
}

Department of Nephrology, Hypertension and Kidney Transplantation, Medical University of Lodz, Central University Hospital, Poland

A - Study Design, B - Data Collection, C - Statistical Analysis, D - Data Interpretation, E - Manuscript Preparation, F - Literature Search, G - Funds Collection

Summary Background. Urinary tract infection (UTI) is one of the most common infection among young women.

Objectives. The study evaluated knowledge and usage of methods of UTI prevention and awareness in women.

Material and methods. 150 women age $\geq 16$ years (mean $23.3 \pm 4.9$ years) took part in the web-based survey: https://profilaktykazum. webankieta.pl/. The survey was disseminated through social media, discussion groups for women and a group blog.

Results. Women identified mostly such methods of UTI prevention as wiping in the correct direction after urination, wearing cotton underwear and increased water consumption, but used these methods with lesser frequency. The respondents were asked to choose the right prevention methods. Nearly a third chose at least one incorrect answer. The recognition of correct UTI prevention methods was higher $(p=0.02)$ among women with a positive history of UTI events. Close relatives, general practitioners and medical specialists remain the main source of knowledge about UTI prevention and management. $63 \%$ of women reported having at least one diagnosed episode of UTI in their lifetime, and $63 \%$ of them sought the help of a general practitioner.

Conclusions. A majority of women have at least one episode of UTI in their lifetime, but despite this, they tend to recognise the condition as benign and neither report it to general practitioners nor take antibiotics. Most females are able to identify the proper methods of UTI prevention, but the utilisation of these methods seems to be insufficient. The survey results could be used by family doctors as educational material to increase awareness of UTI symptoms, prevention and treatment among women.

Key words: surveys and questionnaires, women, urinary tract infection.

Cyran O, Jagodzińska M, Nowicki M. Knowledge and usage of prevention measures against urinary tract infections among young women. Fam Med Prim Care Rev 2019; 21(4): 329-334, doi: https://doi.org/10.5114/fmpcr.2019.90161.

\section{Background}

Urinary tract infection (UTI) is one of the most common infection among young women and the most common disease of the urinary tract in women of all ages. UTI affects as many as $50 \%$ of women at least once during their lifetime [1-3]. Symptomatic urinary tract infections (UTI) are either uncomplicated or complicated. Uncomplicated infections occur in healthy women in society and are mostly caused by Escherichia coli. Complicated infections are associated with anatomical, functional or metabolic abnormalities of the urinary tract that disable the natural innate host defence and lead to tissue injury.

UTIs are a major source of morbidity in young women and generate substantial healthcare costs. Established risk factors of UTI in young women include sexual activity, spermicide-based contraception and a previous history of UTI [4].

There are a number of recommendations that could help women avoid urinary tract infections (UTIs), and the most popular advice includes wiping in the correct direction after urination, increased water consumption, cleaning the bladder area first, emptying the bladder at least every four hours, wearing cotton underwear and avoiding the use of spermicidal jelly $[5,6]$.

Ahmed and Avasara [7] revealed a strong significant association between the prevalence of UTI and improper perineal washing technique. In general, logical hygiene practises are recommended by international guidelines and literature reviews [8-10]. Antimicrobials continue to be the most effective form of UTI treatment. The choice of antimicrobial agent and its dosing and route of administration should be tailored to the individual patient [11].

As included in the current recommendations, clinical studies have shown the effectiveness of a 3-day course of trimethoprim or nitrofurantoin for the treatment of acute uncomplicated cystitis $[8,12]$. Despite this, the European Association of Urologists also recommends fosfomycin, trometamol and pivmecillinam as the treatment of first choice [9].

The use of antibiotics for the treatment of UTI episodes may be limited by non-adherence. According to the recent study of Knottnerus et al. [13] and Butler et al. [14], although most females have antibiotics prescribed by a general practitioner, onethird report not taking the drugs as prescribed.

\section{Objectives}

The objective of our study was to assess the knowledge of risk factors, warning signs and prevention methods for urinary tract infection among young women.

\section{Material and methods}

\section{Study design}

The study involved 150 women over the age of 16 years (mean $23.3 \pm 4.9$ years; upper limit 55 years) interviewed with the web-based, anonymous survey: https://profilaktykazum. webankieta.pl.

Before the start of the study, the questionnaire had been validated in a pilot study of 30 women and was reviewed by experts 
in the field. The questionnaire was prepared by a team of experienced researchers and disseminated by a young female scientist previously involved in the clinical studies in patients with urinary tract infections. The questionnaire was prepared using free, publicly accessible Internet tools. The online questionnaire was accessible for a limited time from 17/02/2017 to 10/06/2017.

The questionnaire consisted of 3 parts and included 17 closed single-choice questions, 5 closed multiple-choice questions and 2 questions designed to measure the response on an interval level (Table 1). In the first part of the survey, women were asked about age, education, place of residence, history of pregnancies and deliveries. In the second part, they were asked about risk factors, warning signs, usage of methods of UTI prevention and the source of their knowledge. The respondents could have chosen the right prevention methods out of 12 answers that were correct and 5 that were incorrect. The incorrect answers were: wipe in the direction from back to front, empty the bladder at least every 6 hours, take prolonged baths, use sanitary pads for periods, use of spermicidal jelly. The third part of the survey was accessible only to the women who reported at least 1 episode of UTI and contained questions about the history of UTI, its treatment with antimicrobial agents and medical care.

\section{Study size}

In the pilot study for this research, we saw that knowledge of UTI prevention methods would be 0.3 times higher in woman who had episodes of UTI compared to those who had not. Therefore, we calculated the minimal required group size with the assumption of the power of chi-square test of at least 0.8 , and it turned out that we needed about 90 participants for the study. As we sought young, sexually active woman concerned about their health, using the Internet medium seemed the most convenient way to get in touch with them.

The study sample included a group of randomly chosen young women. The survey was disseminated through social media, discussion groups for women and a group blog on Doctorb.pl. Other popular websites for women in Poland, including: polki.pl, obcasy.pl, wizaż.pl, papilot.pl, "agata berry-blog", "dbam o siebie-blog", "kobiecy punkt widzenia-blog", "kobieta niezwykła blog", either did not respond to the official e-mail request from our University or refused to add a link to the survey to their websites.

\section{Statistical analysis}

For statistical analysis, Statsoft Statistica v.12 software was used. The data is presented as mean \pm standard deviation and as percentages. The chi-square test of Independence was used to determine if there was a significant relationship between two categorical variables, and $p<0.05$ was considered as significant.

\section{Bias}

We minimised the selection bias by distributing paper versions of the survey throughout randomly chosen women. Moreover, thanks to using a study group much bigger than needed for receiving the statistical significance of the chi-square test, we increased the chance of examining the sample as being more relevant to the actual population.

\section{Ethical consideration}

Approval from the ethics committee was not required for this work, as it was a non-experimental, voluntary survey.

\section{Results}

The study involved 150 women over 16 years of age. The characteristics of study participants (demographic and social data) can be found in Table 1 .

\begin{tabular}{|c|c|}
\hline & $\%$ \\
\hline $\begin{array}{l}\text { Education } \\
\text { junior high school } \\
\text { high school } \\
\text { student } \\
\text { bachelor/engineer } \\
\text { master } \\
\text { doctoral }\end{array}$ & $\begin{array}{l}1.36 \\
2.04 \\
72.79 \\
14.97 \\
8.16 \\
0.68\end{array}$ \\
\hline $\begin{array}{l}\text { Place of residence } \\
\text { village } \\
\text { town up to } 20 \text { thousand residents } \\
\text { town from } 20 \text { thousand up to } 100 \text { thousand residents } \\
\text { town from } 100 \text { thousand up to } 500 \text { thousand residents } \\
\text { town of more than } 500 \text { thousand residents }\end{array}$ & $\begin{array}{l}16.78 \\
11.41 \\
12.08 \\
9.40 \\
50.34 \\
\end{array}$ \\
\hline $\begin{array}{l}\text { Pregnancy/deliveries } \\
0 \\
1 \\
2\end{array}$ & \begin{tabular}{|l}
96 \\
2.67 \\
1.33
\end{tabular} \\
\hline
\end{tabular}

Table 2. Distribution of selected variables for women with and without a positive history of UTI

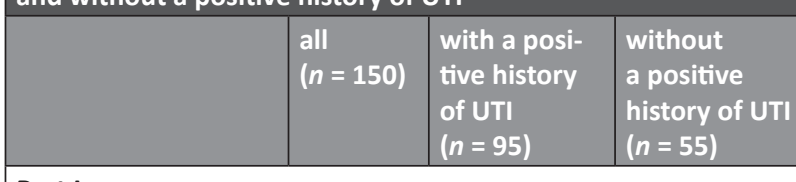

Part I

\begin{tabular}{|l|l|l|l|}
\hline Sexual activity & & & \\
yes & 106 & 80 & 26 \\
no & 37 & 11 & 26 \\
refused to answer & 7 & 4 & 3 \\
\hline $\begin{array}{l}\text { Infection of reproduc- } \\
\text { tive system }\end{array}$ & & & \\
yes & 93 & 77 & 16 \\
no & 57 & 18 & 39 \\
\hline
\end{tabular}

Part II

Number of episodes

of UTI in the past

0-1 19

2-4

$5-7$

$8-10$

Number of UTI

episodes in last 12

months

0

1

2-4

$5-7$

$8-10$

Urinary tract infec-

tions in close female

relatives

yes

\begin{tabular}{|c|c|}
\hline no & 23 \\
\hline $\begin{array}{l}\text { Seeking help of } \\
\text { a general practitioner } \\
\text { yes } \\
\text { no }\end{array}$ & $\begin{array}{l}60 \\
35\end{array}$ \\
\hline $\begin{array}{l}\text { Taking an antibiotic } \\
\text { to treat UTI } \\
\text { yes } \\
\text { no }\end{array}$ & $\begin{array}{l}43 \\
52\end{array}$ \\
\hline
\end{tabular}

$63 \%$ of women reported a history of at least one diagnosed episode of UTI in their lifetime, but $74 \%$ had a history of frequent urination, and $70 \%$ recalled a burning sensation during urination. $63 \%$ of women with at least one UTI sought the help 


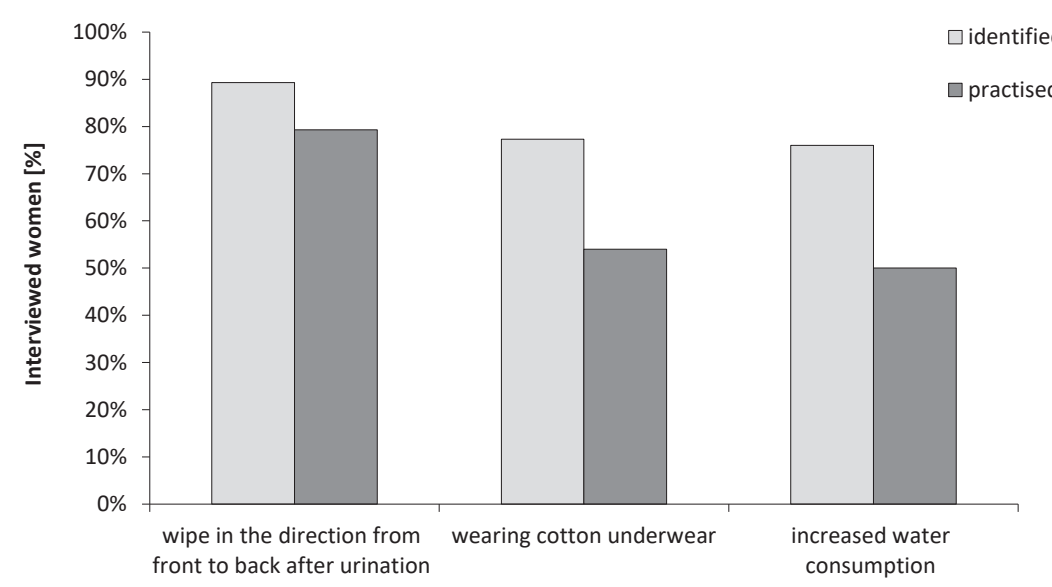

Figure 1. Most frequently identified and practised methods of UTI prevention

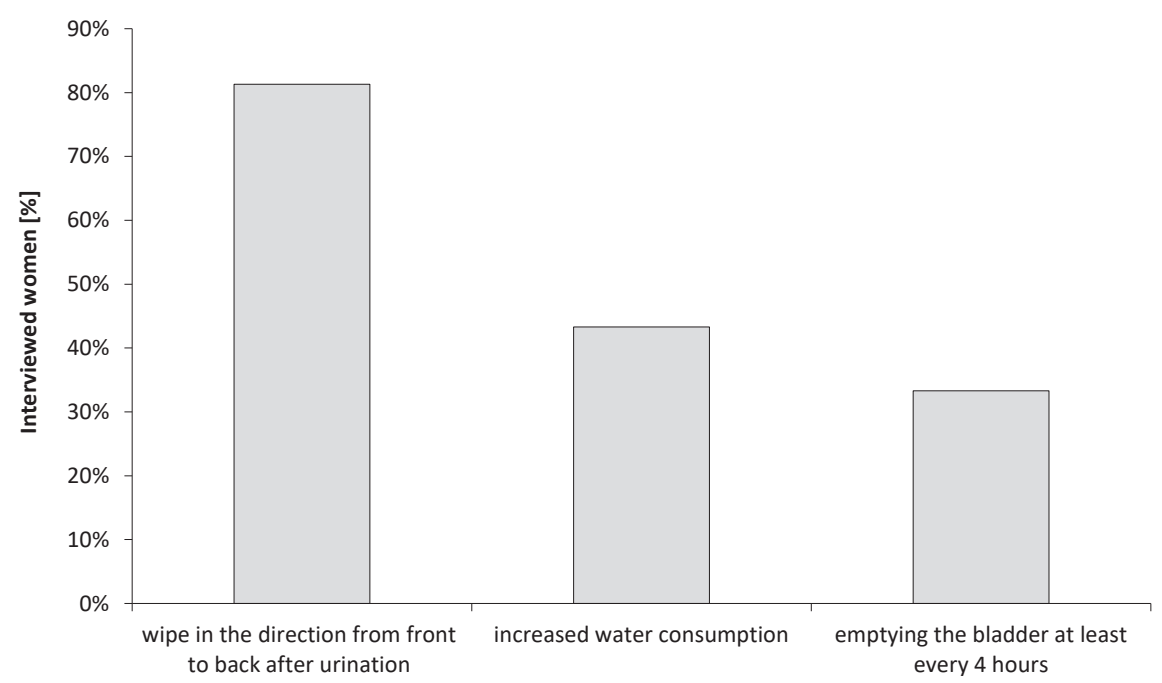

Figure 2. The methods of UTI prevention chosen as the most relevant

of a general practitioner. Only $45.3 \%$ of them reported taking an antibiotic to treat the last episode of UTI. $76 \%$ of women answered yes to the question about urinary tract infections in their close female relatives. Most of the respondents were sexually active (71\%).

Women could choose the proper methods of UTI prevention from the list. Women mostly identified the following methods of prevention: wiping in the direction from front to back after urination $(89.3 \%)$, wearing cotton underwear $(77.3 \%)$ and increased water consumption (76\%) (Figure 1).

Women mostly practised the same methods that they listed, but the percentages were smaller, i.e. wiping in the direction from front to back after urination (79.3\%), wearing cotton underwear (54\%), increased water consumption (50\%) (Fig. 1).

The respondents were also asked to choose the right prevention methods out of 12 answers that were correct and 5 that were incorrect. The incorrect answers were: wipe in the direction from back to front, empty the bladder at least every 6 hours, take prolonged baths, use sanitary pads for periods, use of spermicidal jelly. Over two thirds of all women answer all questions correctly. $30.7 \%$ of women chose at least one incorrect answer. $24.2 \%$ of women who reported having at least one diagnosed episode of UTI in their lifetime and $41.8 \%$ of women who had not experienced any UTI episode chose at least one incorrect answer (chi-squared $=5.079 ; p=0.02$ ).

Knowledge of UTI prevention methods was significantly more prevalent among women with a positive history of a UTI event $(24.2 \%$ vs $41.8 \%$; $p=0.02)$.
The surveyed women were also asked to order the methods of UTI prevention from the most to the least important in their opinion. Most recognised wiping in the correct direction (81.3\%) as the most important, followed by increased water consumption (43.3\%) and emptying the bladder at least every 4 hours (33.3\%) (Figure 2).

The respondents were also asked to rate the severity of the following symptoms on a scale of 0-10: urgency of urination, pain when passing urine, pain in the lower abdomen, low back pain, change of urine appearance, blood in urine and increased frequency of urination. The most bothersome, in their opinion, were the urgency of urination, increased frequency of urination and pain when passing urine (Figure 3 ).

The surveyed women were also asked: "How worried you would be about the following symptoms?"; from the most to the least bothersome: blood in urine, shivers, fever, change of appearance of urine, low back pain, pain in the lower abdomen, pain when passing urine, burning sensation when passing urine, increased frequency of urination (Figure 4).

Close relatives (44\%), general practitioners (40\%) and medical specialists (33.3\%) were the main source of knowledge about UTI.

The most commonly identified pharmacologic methods of UTI treatment were the administration of nitrofurantoin $(87.4 \%)$, the use of dietary supplements containing cranberry juice $(45.3 \%)$ and vitamin C (42\%). 


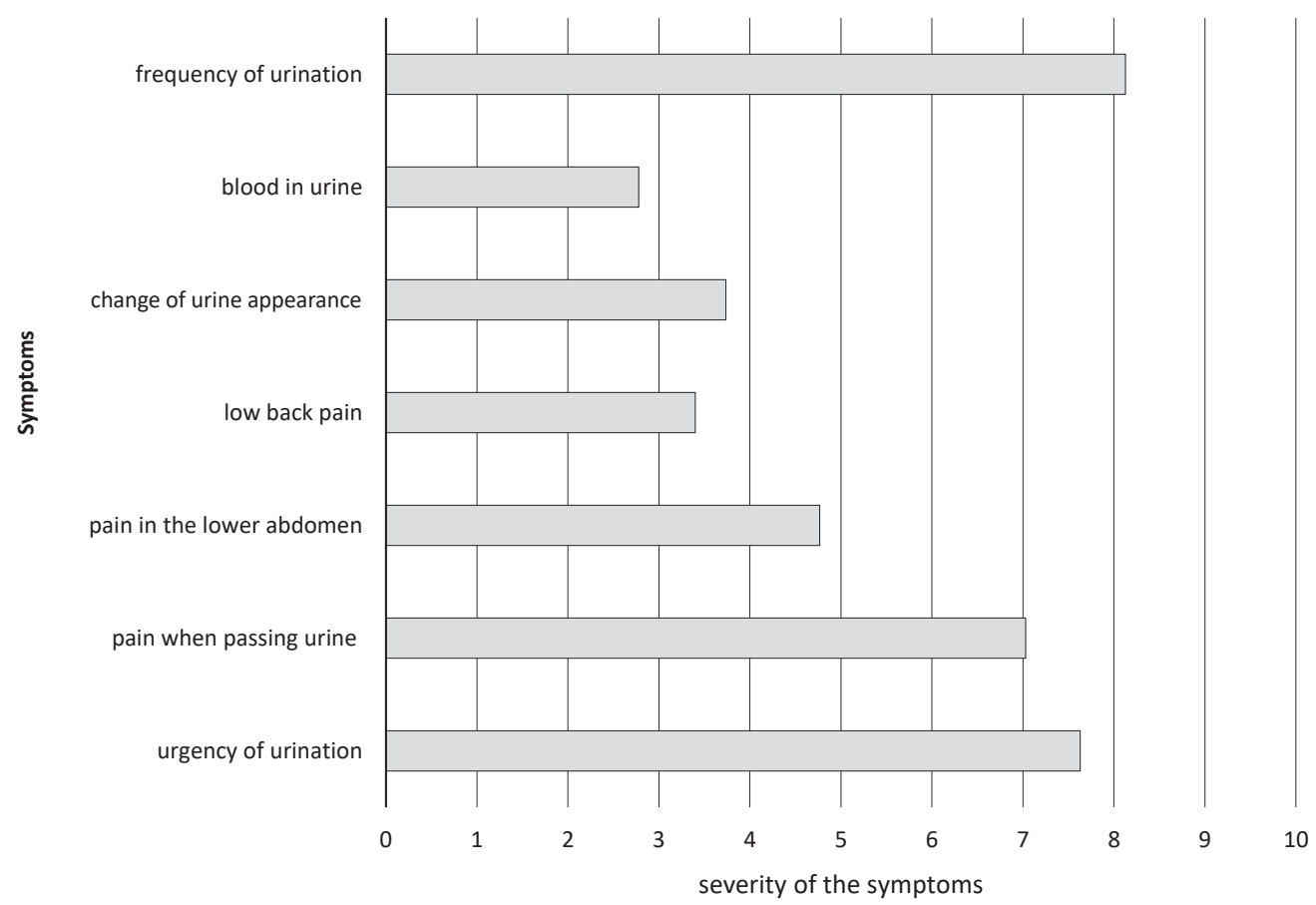

Figure 3. Assessment of the severity of the common symptoms of urinary tract infection

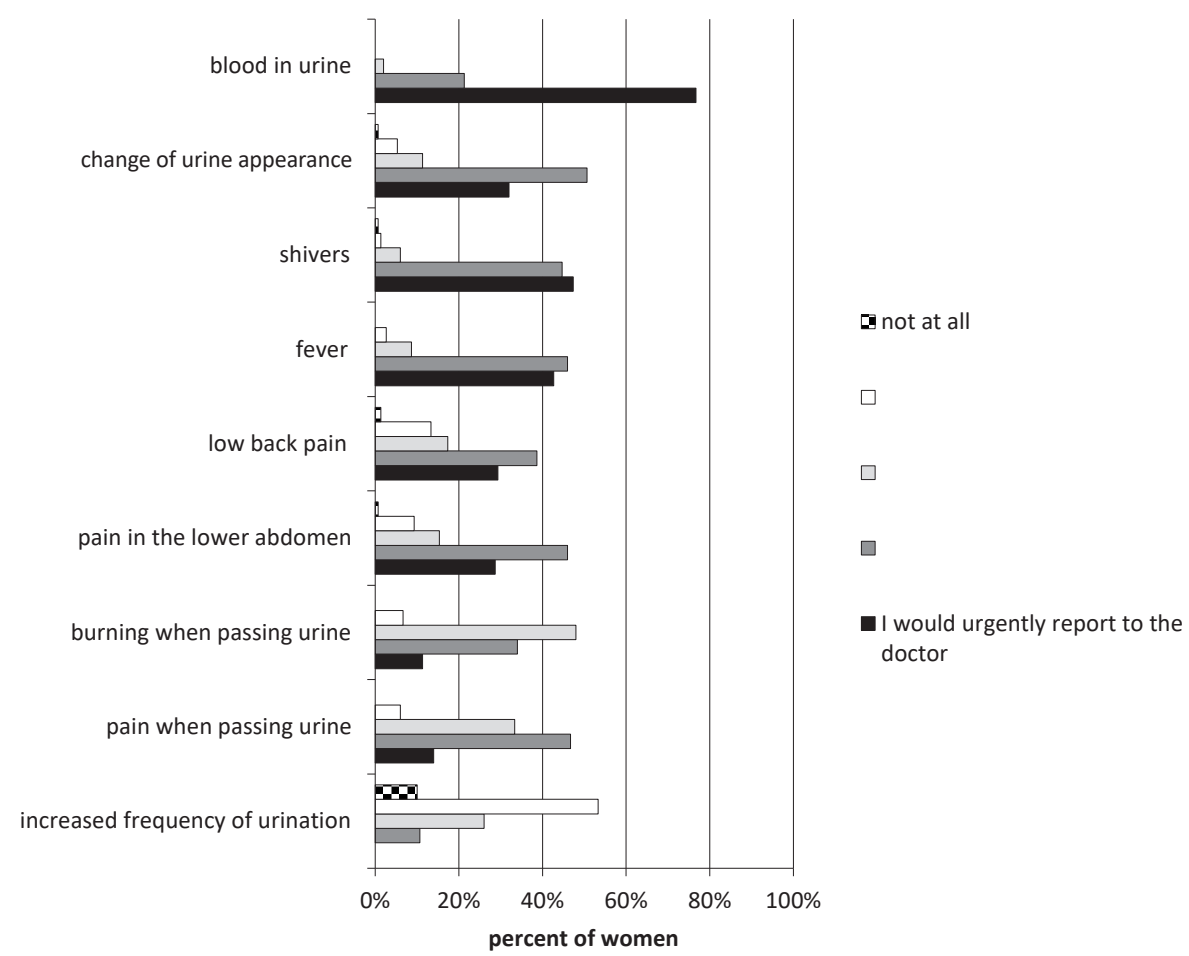

Figure 4. Responses to the question: how worried you would be about the following symptoms?

\section{Discussion}

The knowledge of women about the prevention methods of urinary tract infections and their risk factors has hardly been investigated despite the high prevalence of UTI and its high clinical relevance in this population [5]. Most of the studies on UTI prevention involved pregnant and elderly women or women suffering from chronic diseases, such as diabetes, or receiving immunosuppressive drugs [15-17]. In contrast, our study was carried out among young women. The surveyed women were active Internet users. Such population could differ from the gen- eral population since, according to the several studies [18, 19], new media could have a significant influence on lifestyle and sexual behaviour in young people. Young women are a group at increased risk of UTI. Most of our respondents were sexually active, whereas some well-identified risk factors for UTI include sexual activity and spermicide-based contraception [4]. Among sexually active young women, the incidence of symptomatic urinary tract infection is higher, and the risk is strongly and independently associated with recent sexual intercourse $[1,10$, $20,21]$. The online questionnaire is a well-adapted method for this group of women [22-25]. The layout, graphics and the form of our questionnaire were also tailored to the target group. 
In web-based surveys, there is an unavoidable selection bias due to the non-representative nature of the Internet population, as well as through the self-selection of participants, i.e. the non-representative nature of respondents, also called the 'volunteer effect'. Self-selection bias comes from the fact that people are more likely to respond to questionnaires if they see items, e.g. health issues, that interest them [23].

Unfortunately, access to the dissemination of the questionnaire through popular websites for women was limited. To our surprise, most popular Polish online portals for young women did not respond to the official e-mail requests from our University or refused to collaborate. Due to the difficulties in the dissemination of the questionnaire, the group of questioned women was relatively small.

As mentioned above, UTI is highly prevalent among young women. Both our study and previous studies $[1-3,26]$ showed that over half of all women experienced UTI during their lifetime.

Histories of reproductive tract infection were more common in the group of women with a positive history of UTI events than in the group of women without UTI. This was confirmed by others, e.g. Scholes et al. [4]. The largest part of the women surveyed in our study had a history of 1-4 episodes of UTI, which was also found in a study by Scholes et al. [4].

The same study [4] showed the close association between recurrent urinary tract infections and the use of contraceptives, infrequent or no post-coital voiding, delayed voiding, wiping from back to front after urination, use of non-cotton underwear and decreased water consumption. Our online questionnaire included these common behaviours. Of note is that most females in our study were able to identify the proper methods of UTI prevention. It should also be noted that knowledge of UTI prevention methods was statistically significantly more prevalent among women with a positive history of a UTI event.

Using sanitary pads for periods and delayed voiding were the most frequently selected incorrect answers in our study and a highly prevalent behaviour in patients with UTI history, as shown in the studies of Scholes et al. [4] and Foxman et al. [27]. Interestingly, the most recognised methods of prevention of urinary tract infection and those that were identified as the most relevant by the surveyed women were used only by a small proportion of women in that study [4].

The women in our study mostly practised the same methods that were listed as the most important for UTI prevention; however, the percentages of those using them were smaller. We have not been able to find any other study to directly compare our results with in this aspect.
Our study also addressed a practical issue, i.e. how bothersome were UTI symptoms to young women. Our results confirm some previous analyses. As discussed by Colgan et al. [1] and Clayson et al. [28], frequent urination, urgency of urination and pain when passing urine were the most bothersome symptoms reported by women. The same was found in our study, with a high score of 7-8 on a 10-point scale. As mentioned by Butler et al. [14], severe and/or persistent symptoms were the main reasons for visiting a healthcare professional by women with UTI. We have revealed that the most common cause for urgent medical visits were blood in urine, shivers, fever and change in the appearance of urine.

The same study [14] confirms our observation about seeking help. Most females were treated by a general practitioner and were prescribed antibiotics, but a significant part reported not taking the antibiotics as prescribed.

\section{Limitations of the study}

Our study has several limitations. The population of the questioned women was quite small and might not represent the majority of young women. Furthermore, the difficulties in the dissemination of the questionnaire could lead to a selection bias. It was also difficult to critically discuss the findings of women's knowledge on UTI prevention, since we were not able to find any similar study that was focused on the knowledge of young women on the prevention of UTI.

Our survey is innovative in this respect. It is worth pointing out that the survey was also informative, because the surveyed women could check their answers after completion and could therefore learn about prevention.

\section{Conclusions}

Although most women experience UTI in their lifetime, it is still recognised as a benign condition, and only a fraction report the problem to a general practitioner and take antibiotics. Publicly available Internet-based medical services supervised by professionals could become the primary source of knowledge about urinary tract infection for women. Such validated tools could be used by family doctors as important educational material that may increase the awareness of UTI symptoms, prevention and treatment among women in different age groups.

Most females are able to identify the proper methods of UTI prevention, but utilisation of the methods is insufficient. The knowledge of UTI prevention methods mostly depends on a previous history of UTI.

Source of funding: This work was funded by the Medical University of Lodz.

Conflicts of interest: The authors declare no conflicts of interest.

\section{References}

1. Colgan R, Keating K, Dougouih M. Survey of symptom burden in women with uncomplicated urinary tract infections. Clin Drug Investig 2004; 24: 55-60.

2. Chaudhuri SR, Thakur AR, Nandy P, et al. Urinary tract infection - a survey of local population. Am J Infect Dis 2008; 4: 117-123.

3. Al-Badr A, Al-Shaikh G. Recurrent urinary tract infections management in women: a review. Sultan Qaboos Univ Med J 2013; 13: 359-367.

4. Scholes D, Hooton TM, Roberts PL, et al. Risk factors for recurrent urinary tract infection in young women. J Infect Dis 2000; 182: 1177-1182.

5. Foxman B. Epidemiology of urinary tract infections: incidence, morbidity, and economic costs. Dis Mon 2003; 49: 53-70.

6. Behzadi $\mathrm{P}$, Behzadi $\mathrm{E}$, Yazdanbod $\mathrm{H}$, et al. A survey on urinary tract infections associated with the three most common uropathogenic bacteria. Maedica (Buchar) 2010; 5: 111-115.

7. Ahmed SM, Avasara AK. Urinary tract infections (UTI) among adolescent girls in rural Karimnagar District, AP K.A.P. STUDY. Indian J Pre Soc Med 2008; 39: 12-15.

8. National Institute for Health and Care Excellence. Urinary tract infection (2016) [cited 06.06.2019]. Available from URL: https://www. nice.org.uk/guidance/ng109/chapter/recommendations\#choice-of-antibiotic

9. EAU Guidelines. Edn. presented at the EAU Annual Congress Copenhagen 2018. ISBN 978-94-92671-01-1.

10. Smith AL, Brown J, Wyman JF, et al. Treatment and prevention of recurrent lower urinary tract infections in women: a rapid review with practice recommendations. J Urol 2018; 1174-1191, doi: 10.1016/j.juro.2018.04.088. 
11. Beerepoot MA, Geerlings SE, van Haarst EP, et al. Non-antibiotic prophylaxis for recurrent urinary tract infections: a systematic review and meta-analysis of randomized controlled trials. J Urol 2013; 190: 1981-1989.

12. Scottish Intercollegiate Guidelines Network. Sign 88: Management of suspected bacterial urinary tract infection in adults. A national clinical guideline. Edinburgh: Scottish Intercollegiate Guidelines Network; 2012 [cited 06.06.2019]. Available from URL: https://www. sign.ac.uk/sign-88-management-of-suspected-bacterial-urinary-tract-infection-in-adults.html.

13. Knottnerus BJ, Geerlings SE, Moll van Charante EP, et al. Women with symptoms of uncomplicated urinary tract infection are often willing to delay antibiotic treatment: a prospective cohort study. BMC Fam Pract 2013;14:71.

14. Butler CC, Hawking MK, Quigley A, et al. Incidence, severity, help seeking, and management of uncomplicated urinary tract infection: a population-based survey. Br J Gen Pract 2015; 65: 702-707.

15. Genao L, Buhr GT. Urinary tract infections in older adults residing in long-term care facilities. Ann Longterm Care 2012; 20 : 33-38.

16. Nicolle LE. Urinary tract infections in special populations: diabetes, renal transplant, HIV infection, and spinal cord injury. Infect Dis Clin North Am 2014; 28: 91-104.

17. Glaser AP, Schaeffer AJ. Urinary tract infection and bacteriuria in pregnancy. Urol Clin North Am 2015; 42: 547-560.

18. Techasrivichien T, Darawuttimaprakorn N, Punpuing $S$, et al. Changes in sexual behavior and attitudes across generations and gender among a population-based probability sample from an urbanizing province in Thailand. Arch Sex Behav 2016; 45: 367-382.

19. Gruber E, Grube JW. Adolescent sexuality and the media: a review of current knowledge and implications. West J Med 2000; 172: 210-214.

20. Epp A, Larochelle A, Saskatoon SK, et al. (Urogynaecology Committee, Family Physicians Advisory Committee). Recurrent urinary tract infection. J Obstet Gynaecol Can 2010; 32(11): 1082-1090, doi: 10.1016/S1701-2163(16)34717-X.

21. Vincent $\mathrm{CR}$, Thomas TL, Reyes $\mathrm{L}$, et al. Symptoms and risk factors associated with first urinary tract infection in college age women: a prospective cohort study. J Urol 2013; 189: 904-910.

22. Riva G, Teruzzi T, Anolli L. The use of the internet in psychological research: comparison of online and offline questionnaires. Cyberpsychol Behav 2003; 6(1): 73-80.

23. Eysenbach G, Wyatt J. Using the internet for surveys and health research. J Med Internet Res 2002; 4(2): e13, doi: 10.2196/jmir.4.2.e13.

24. Klovning A, Sandvik H, Hunskaar S. Web-based survey attracted age-biased sample with more severe illness than paper-based survey. J Clin Epidemiol 2009; 62: 1068-1074.

25. van Gelder MM, Schouten NP, Merkus PJ, et al. Using web-based questionnaires and obstetric records to assess general health characteristics among pregnant women: a validation study. J Med Internet Res 2015; 17(6): e149, doi: 10.2196/jmir.3847.

26. Jermakow K, Pajączkowska M, Krzyżanowska B, et al. The growing importance of Enterococcus and Streptococcus agalactiae in uncomplicated urinary tract infections. Fam Med Prim Care Rev 2016; 18(3): 250-252, doi: 10.5114/fmpcr/63176.

27. Foxman B, Gillespie B, Koopman J, et al. Risk factors for second urinary tract infection among college women. Am J Epidemiol 2000; 151: 1194-1205.

28. Clayson $D$, Wild $D$, Doll $H$, et al. Validation of a patient-administered questionnaire to measure the severity and bothersomeness of lower urinary tract symptoms in uncomplicated urinary tract infection (UTI): the UTI Symptom Assessment questionnaire. BJU Int 2005; 96: 350-359.

Tables: 2

Figures: 4

References: 28

Received: 24.05.2019

Reviewed: 12.06 .2019

Accepted: 8.07.2019

Address for correspondence:

Prof. Michał Nowicki

Klinika Nefrologii, Hipertensjologii i Transplantologii Nerek UM

ul. Pomorska 251

92-213 Łódź

Polska

Tel.: +48 42 201-44-00

E-mail: nefro@wp.pl 